\title{
Деформация тонких пленок полуметаллов методом купольного изгиба подложки
}

\author{
(C) А.В. Суслов, В.А. Герега, В.М. Грабов, Е.В. Демидов, В.А. Комаров \\ Российский государственный педагогический университет им. А.И. Герцена, \\ 191186 Санкт-Петербург, Россия \\ E-mail: a.v_suslov@mail.ru
}

Поступила в Редакцию 20 октября 2021 г.

В окончательной редакции 25 октября 2021 г.

Принята к публикации 25 октября 2021 г.

\begin{abstract}
Представлены результаты исследования деформации пленок полуметаллов, создаваемой путем купольного изгиба подложки. Контроль деформации проводился методами рентгеноструктурного анализа. Показано, что метод купольного изгиба может быть использован для исследования пленок в условиях плоскостной деформации, возникающей в системе пленка-подложка вследствие различия коэффициентов температурного расширения материала пленки и подложки. Установлено, что деформация, создаваемая купольным изгибом подложки в сочетании с использованием подложек с различным температурным расширением, позволяет получить относительную плоскостную деформацию пленок висмута вплоть до $0.8 \%$ при $300 \mathrm{~K}$.
\end{abstract}

Ключевые слова: висмут, полуметаллы, тонкие пленки, деформация, рентгеноструктурный анализ, коэффициент температурного расширения, купольная деформация.

DOI: 10.21883/FTP.2022.02.51958.31

\section{1. Введение}

В последние несколько лет вновь возродился интерес к изучению эффектов, связанных с влиянием деформации на физические свойства материалов, ввиду развития стрейнтроники [1]. Висмут и его сплавы, как хорошие модельные материалы, представляют существенный интерес в этой связи. В работе [2] на основе теории функционала плотности показано, что при одноосной деформации сжатия массивного монокристалла висмута вдоль оси $C_{3}$, вызываемой повышением давления, происходит переход полуметалл-полупроводник в области отношения постоянных решетки $c / a=2.41-2.51 \mathrm{c}$ максимумом ширины запрещенной зоны при $c / a=2.45$. В этом состоянии ожидается повышение коэффициента термоэдс и уменьшение теплопроводности, что, несмотря на уменьшение удельной проводимости, приводит к росту ZT. В работе [3] при исследовании классических термоэлектрических материалов на основе $\mathrm{Bi}_{2} \mathrm{Te}_{3}$ также показано сильное влияние деформации на зонную структуру.

В работах [4-6] нами было показано экспериментально наблюдаемое сильное влияние плоскостной деформации, возникающей в системе пленка-подложка вследствие различия коэффициентов температурного расширения этих материалов, на гальваномагнитные и термоэлектрические свойства пленок висмута и висмутсурьма. В работе [7] теоретически и экспериментально показано влияние несоответствия постоянных решетки ультратонких пленок висмута на зонную структуру методами теории функционала электронной плотности. Данный тип деформации отличается от деформации, возникающей вследствие гидростатического давления, смоделированного в работах $[1,2]$, так как при уменьше- нии отношения $c / a$ происходит сжатие в направлении тригональной оси $C_{3}$ и растяжение в перпендикулярном направлении, в то время как при гидростатическом сжатии происходит сжатие в обоих направлениях.

Для экспериментального исследования пленок висмута в условиях деформации растяжения в плоскости пленки нами был изготовлен специальный держатель образцов. Контролю величины и диапазона деформации пленок висмута, получаемой данным методом, посвящена настоящая работа.

\section{2. Методика эксперимента}

Идея разработанного метода представлена в работе [8]. Метод основан на купольном изгибе подложки со сформированной на ней пленкой (рис. 1). При больших радиусах кривизны изгиба подложки и достаточно малых размерах пленки в первом приближении можно считать, что пленка оказывается растянутой в плоскости пленки, что эквивалентно сжатию вдоль нормали к плоскости пленки. Величина деформации задается смещением плунжера, которое контролируется микрометром. Максимум деформации ограничен пределом упругости пленки и подложки.

Пленки чистого висмута толщиной 1 мкм были получены методом термического испарения в вакууме $10^{-5}$ Торр при температуре подложки в процессе испарения $383 \mathrm{~K}$ с последующим отжигом при $523 \mathrm{~K}$ в течение 1 ч. Данные параметры выбраны в целях получения пленок с наиболее совершенной кристаллической структурой. В качестве температуры формирования вследствие релаксации механических напряжений была принята температура отжига. 


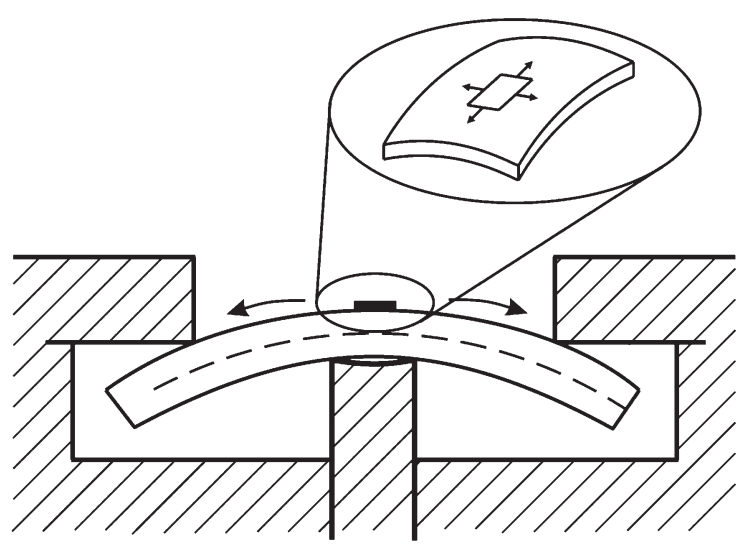

Pис. 1. Схема создания плоскостной деформации пленки с помощью купольного изгиба подложки.

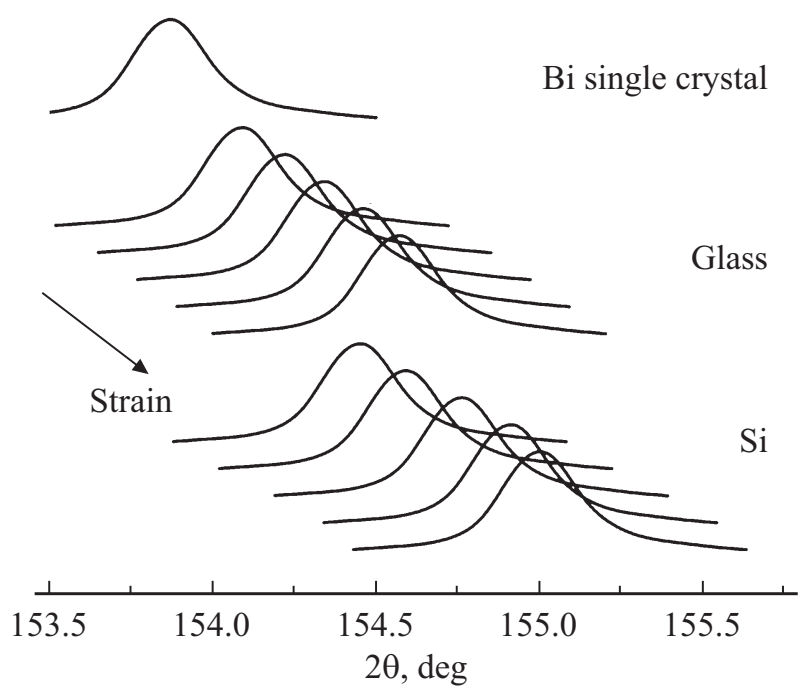

Рис. 2. Иллюстрация смещения пиков в зависимости от подложки и величины купольной деформации.

Для контроля величины и диапазона упругой деформации, создаваемой купольным изгибом пленки с подложкой, был изготовлен держатель, позволяющий измерить межплоскостное расстояние в деформированном пленочном кристалле с использованием дифрактометра ДРОН-7. С помощью данного держателя образца был получен ряд дифрактограмм от пленки висмута в условиях различной купольной деформации, задаваемой положением плунжера, которое контролировалось микрометром. В качестве характеристики величины деформации используется смещение дифракционных максимумов при перемещении плунжера (рис. 2).

Учитывая то, что пленка при комнатной температуре уже находится в деформированном состоянии вследствие различия температурного расширения материала пленки и подложки, нами были исследованы пленки висмута (коэффициент температурного расширения (КТР) в плоскости (111) равен $11.2 \cdot 10^{-6} \mathrm{~K}^{-1}$ ) на подложках с различным температурным расширением: из боросиликатного стекла (КТР равен $8 \cdot 10^{-6} \mathrm{~K}^{-1}$ ) и кристаллического окисленного кремния (КТР равен $2.33 \cdot 10^{-6} \mathrm{~K}^{-1}$ ). Подложка из кремния с аморфной окисленной поверхностью позволяет получить кристаллическую структуру пленки висмута, аналогичную пленкам на стекле, но имеет КТР значительно меньше, чем у стекла. При температуре ниже температуры формирования пленка висмута на используемых подложках оказывается растянутой в плоскости подложки, причем тем сильнее, чем больше различие КТР материалов пленки и подложки. Величина относительной деформации может быть оценена по формуле

$$
\frac{\Delta S}{S}(T)=\exp \left[2 \int_{T_{0}}^{T}\left(\alpha_{\text {sub }}(T)-\alpha_{f}(T)\right) d T\right]-1,
$$

где $\alpha_{f}$ и $\alpha_{\text {sub }}-$ соответственно КТР пленки и подложки, $T_{0}$ - температура формирования пленки.

Так, при температуре $300 \mathrm{~K}$ величина относительной деформации растяжения пленок висмута на стекле и кремнии $\Delta S / S$ составляет 0.18 и $0.43 \%$ соответственно. Данные значения позволяют привести в соответствие величину положения максимума пятого порядка и величину относительной деформации пленки.

\section{3. Экспериментальные результаты и их обсуждение}

Дифрактограммы, полученные от плоскости пленок, показали, что они имеют блочную структуру с ориентацией плоскости (111) параллельно подложке. Большие размеры кристаллитов и их относительно малая дефектность позволяют хорошо различить максимум пятого порядка (0015) (рис. 3). Данный максимум будет иметь наибольшее смещение при изменении деформации, что позволяет повысить точность исследований.

На рис. 4 представлена зависимость положения максимума пятого порядка (0015) от смещения плунжера $\Delta x$ при деформации пленок висмута на подложках из стекла и кремния с окисленной поверхностью. До значений

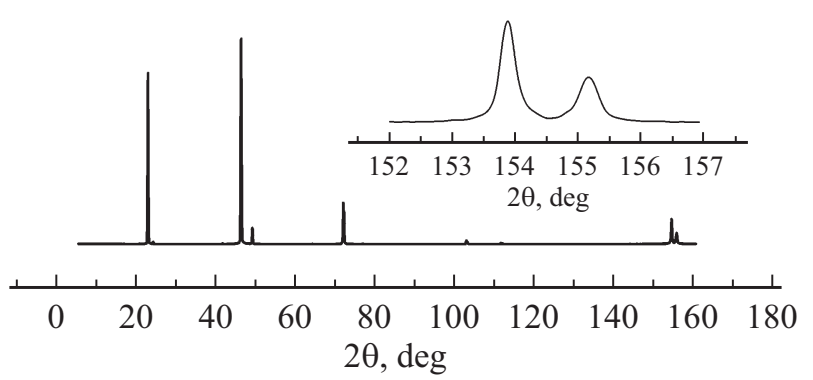

Рис. 3. Дифрактограмма пленки висмута. На вставке - пик пятого порядка (0015). 


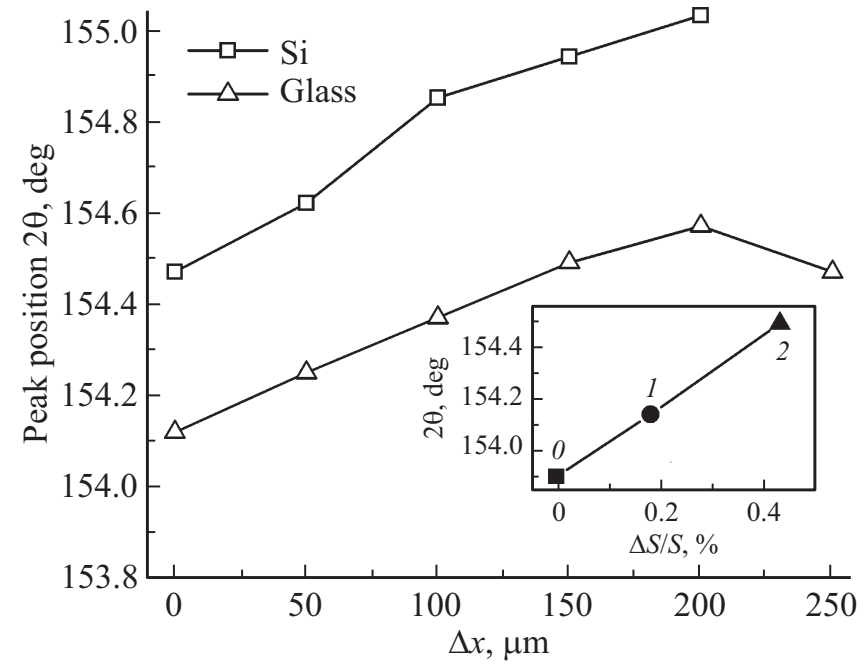

Pис. 4. Зависимость положения пика пятого порядка висмута (0015) от смещения плунжера. На вставке - положение пика пятого порядка массивного монокристалла висмута $(0)$, пленок висмута на подложке из стекла (1) и кремния (2) в зависимости от относительной деформации по площади $\Delta S / S$.

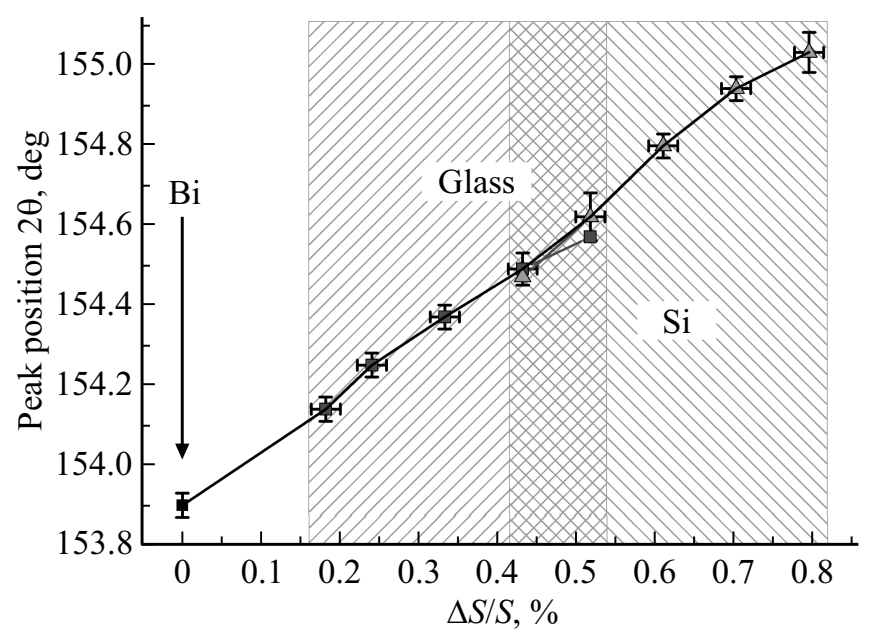

Рис. 5. „Сшитая“ зависимость положения пика пятого порядка висмута (0015) от относительно плоскостной деформации $\Delta S / S$.

смещения плунжера менее 200 мкм наблюдается линейная зависимость положения максимума пятого порядка. При большем смещении наблюдается отклонение от линейности и разрушение подложки. На вставке изображена зависимость положения максимума пятого порядка для пленок висмута на недеформированных подложках от относительной деформации, возникающей вследствие различия КТР пленки и подложки, рассчитанной по формуле (1). При этом положение максимума для монокристалла висмута принято за нуль деформации. Это позволяет „сшить“ зависимости положения пика пятого порядка пленок на подложках из стекла и кремния и привести их в зависимости от относительной деформации.
Данная зависимость представлена на рис. 5. Зависимость хорошо линеаризуется в пределах погрешности эксперимента, что указывает на возможность использования данного подхода для создания непрерывной контролируемой плоскостной деформации вплоть до $\Delta S / S=0.8 \%$ при температуре $300 \mathrm{~K}$.

\section{4. Заключение}

Таким образом, в работе показана эквивалентность плоскостной деформации растяжения, создаваемой купольным изгибом подложки, и деформации, возникающей вследствие различия коэффициентов температурного расширения материалов пленки и подложки. Купольная деформация в сочетании с использованием подложек с различным температурным расширением позволяет получить относительную плоскостную деформацию вплоть до $0.8 \%$ при $300 \mathrm{~K}$. Установленные закономерности позволяют контролировать большие значения деформации, которые могут быть достигнуты в низкотемпературных измерениях вследствие различия КТР пленки и подложки.

\section{Благодарности}

Работа выполнена в рамках государственного задания при финансовой поддержке Министерства просвещения России (проект № FSZN-2020-0026).

\section{Конфликт интересов}

Авторы заявляют, что у них нет конфликта интересов.

\section{Список литературы}

[1] А.А. Бухараев, А.К. Звездин, А.П. Пятаков, Ю.К. Фетисов. УФН, 188], 1288 (2018).

[2] C.Y. Wu, J.C. Han, L. Sun, H.R. Gong, C.P. Liang. J. Phys.: Condens. Matter, 30, 285504 (2018).

[3] T. Inamoto, M. Takashiri. J. Appl. Phys., 120, 125105 (2016).

[4] Н.С. Каблукова, Е.В. Демидов, В.А. Комаров, Е.Е. Христич. Изв. РГПУ им. А.И. Герцена, 153, 13 (2012).

[5] В.М. Грабов, Е.В. Демидов, В.А. Комаров, А.В. Суслов, М.В. Суслов. Письма ЖТФ, 44 (11), 71 (2018).

[6] А.В. Суслов, В.М. Грабов, В.А. Комаров, Е.В. Демидов, С.В. Сенкевич, М.В. Суслов. ФТП, 53 (2), 616 (2019).

[7] T. Hirahara, N. Fukui, T. Shirasawa, M. Yamada, M. Aitani, H. Miyazaki, M. Matsunami, S. Kimura, T. Takahashi, S. Hasegawa, K. Kobayashi. PRL, 109, 227401 (2012).

[8] В.М. Грабов, Е.В. Демидов, В.А. Комаров, С.В. Сенкевич, А.В. Суслов. Поверхность. Рентгеновские синхротронные и нейтронные исследования, 7, 108 (2021).

Редактор А.Н. Смирнов 


\section{Deformation of thin films of semimetals by dome bending of the substrate}

A.V. Suslov, V.A. Gerega, V.M. Grabov, E.V. Demidov, V.A. Komarov

Herzen State Pedagogical University, 191186 St. Petersburg, Russia

Abstract The results of a study of the semimetal films deformation produced by dome bending of the substrate are presented. Deformation control was carried out by means of $X$-ray diffraction analysis. It is shown that the dome bending method can be used to study films under planar deformation in a film-substrate system with different thermal expansion coefficients. The maximum inplane deformation for bismuth films of $1 \mathrm{mkm}$ thickness order was found. It was shown that the deformation created by the dome bending of the substrate in combination with the use of substrates with different temperature expansion makes it possible to obtain a relative in-plane deformation of bismuth films up to $0.8 \%$ at $300 \mathrm{~K}$. 